\title{
A terra, o homem e o bacilo de Koch
}

\begin{abstract}
1
Já vai bemi lonje o tempo em que se considerava a tuberculose 'como doença de poetas. Niessa quadra bolorenta do rapé e da anquinha, cheia de enluarado sentimentalismo ,em que os homens cantavam o luar e andavam de carro de boi ,essa molestia era considerada como aristocrata.

Mas o tempo e a evolução, mais fortes que Lenine, menos sanguinarios que Danton, democratizaram o bacilo de Koch. O que não se conseguiu entre os homens, alcançou-se entre as molestias. Si ainda ha pobres e ricos, magros e gordos, cretinos e esclarecidos, todos poderão ser tuberculozos.
\end{abstract}

$\mathrm{Ha}$ mesmo muito idiota sadio. $\mathrm{E}$ intelligentes dispeticos, diarreicos ou hemorrhoidarios.

Mas eu absolutamente não quero discutir a dezigualdade humana. $E^{\prime}$ un assunto inutil e pouco interessante. Melhor e mais aproveitavel é escrever sobre a anormalidade dos homens. Aliás todos nós o somos. Uns mais que os outros.

Eu, talvez, mais que o leitor. O leitor mais do que pensa sêr.

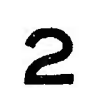

Avolumla-se num crecendo de proporções geométricas, a tuberculose em nosso paiz. Em 925 morreram no Rio 5000 pessoas dessa molestia. Em S. Paulo toda a semana aumentam os cazos. As estatisticas revelam que as perdas devidas as molestias reputadas epidemicas são minimas comparadas á detruição da população pela endemia tuberculoza. Ademais, a mortalidade não dá idéa exacta da frequencia do mal. E' precizo enumerar tambem os cazos que não matando, diminuem o valồr social do individuo . 


\section{3}

E' possivel a luta contra a tuberculoze?

Eu sei que não é um problema de facil solução. Eu creio, mesmo, que é muito complexo e dispendioso.

Sobre a tuberculoze tem-se feito numerosas conferencias; politicos, ministros e mesmo alguns" médicos já fizeram bélos idiscursos.

Esta literatura posta a parte, pouca coiza se tem feito.

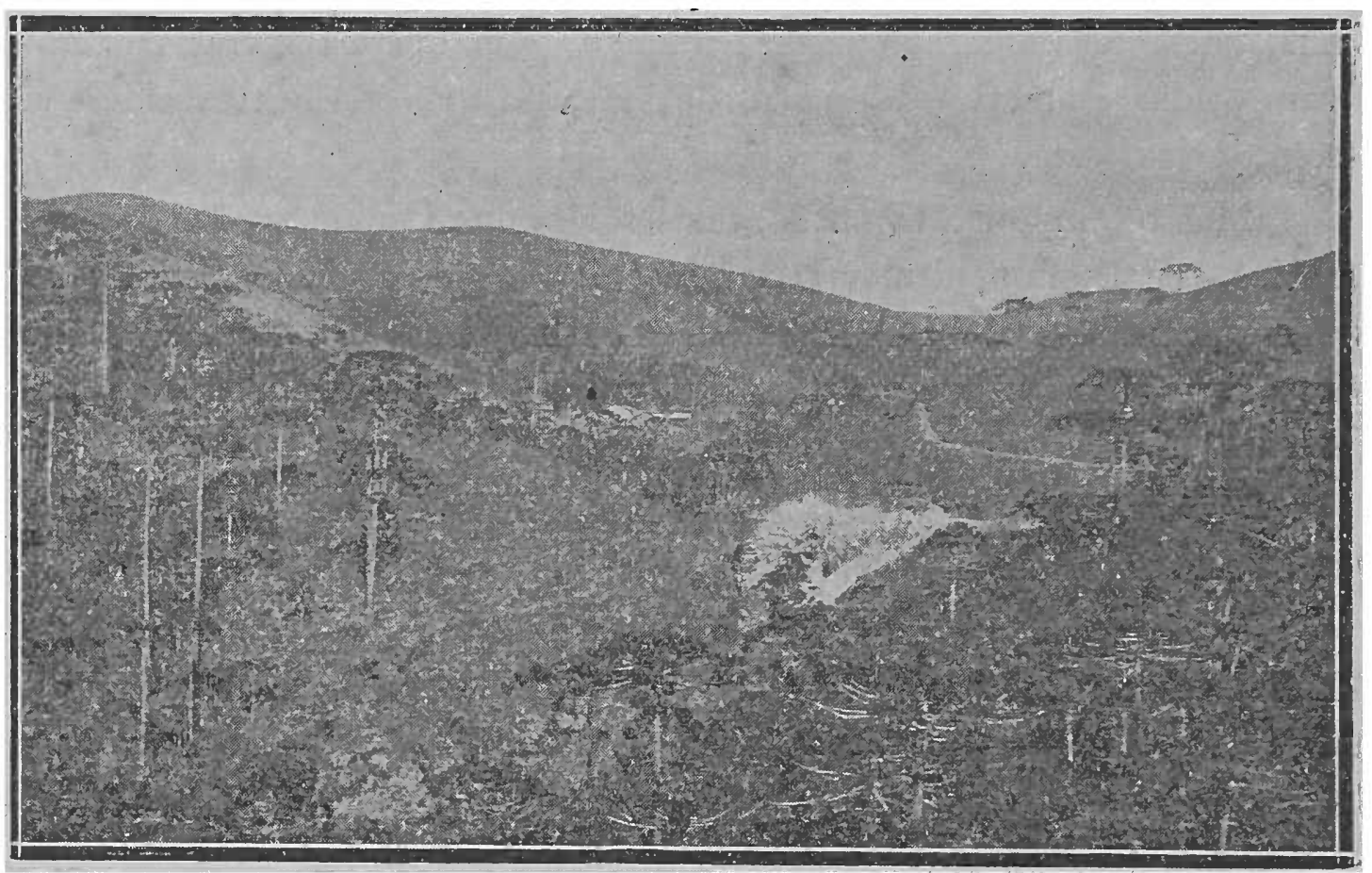

Uma vista de Campos do Jordão

Da iniciativa particular temos diversos dispensarios e o sanatorio "Vicentina Aranha", em São José dos Campos. Embora esta instituiçãço seja modelar, os enfermos pobres lá não podem internar-se devido ao elevado preço.

E não se deve dar saude, apenas aos ricos.

Dos processos empregados na luta social contra a tuberculoze, o unico realmente produtivo é o isolamento do doente e a construção de sanatorios em climas determinados. 


\section{4}

Temos em S. Paulo Campos do Jordão que pelas suas condições especiaes, de clima, temperatura e latitude, é naturalmente indicado para os enfraquecidos, pré-tuberculozos e tuberculozos.

Deitado sobre o planalto da Serra da Mantiqueira, com 1700 metros de altitude, Campos do Jordão é a terra ideal para a construção dum sanatorio e dum hotel confortavel para os debilitados e cansados da civilização.

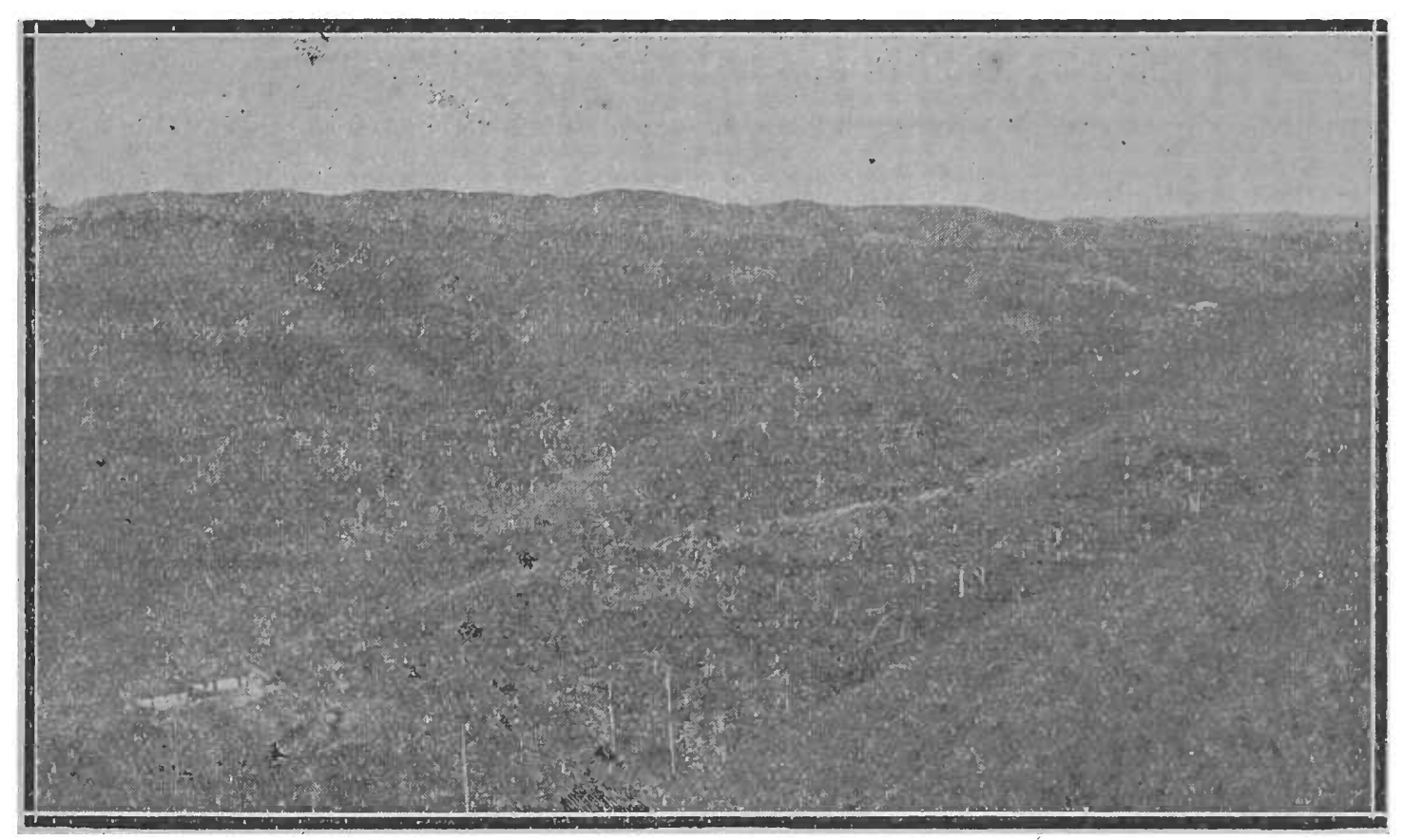

Uma vista de Campos do Jordão

A sua conformação, ondulante e montanhoza, não possui a aridez das planicies do sul e o protege dos ventos impetuozos do oceano.

A natureza pintou Campos do Jordão com esbanjamentos de luz e de côres: montanhas verdes voando pelos ares como revoadas de periquitos; frondozos pinheiraes como gigantescos candelabros lançam seus braços longos e tortuozos para o infinito. E' um ambiente festivo. A paizagem dansa e canta.

$\mathrm{Ha}$ uma alegria carnavalesca nessa vizão panoramica. Tudo é vida'e movimento. 


\section{5}

Como estação tizioterápica Campos do Jordão supera as melhores ido mundo como Leisin, "Davos-Platz" e outras.

$\mathrm{E}$ isso o demonstrou o Prof. A. Fialho, da Faculdade de Medicina do Rio, em documentado trabalho.

Possui baixa pressão barómetrica; abundancia de radiações violetas e ultra-violettas; ar purissimo; fraco gráu higrométrico. Inicialmente aceléra a respiração; poucos dias depois, após néo-formação hemoglominurica, o ritmo respiratorio se torna normal. A ampliação dos movimentos respiratorios produz funcionamento de todos os musculos inspiradores e das partes as mais afastadas e "preguiçozas" do pulmão. Com o aumento da actividade pulmonar, os movimentos do coração são acelerados. O sángue procura a perferia e os orgãos centraes ficam descongestionados. $\mathrm{Ha}$ maior combustão organica. Intensa néo-formação de globulos vermelhos; mais de $1 \mathrm{mi}$ 1hão. Ar sequissimo. Temperatura equilibrada. Nlota-se um aumento notavel do apetite. Digesttão facil e rápida. Absolve-se e fixa-se uma notavel quantidade de nitrogenio e fosforo. A agua é magnifica e de ação radio-activa.

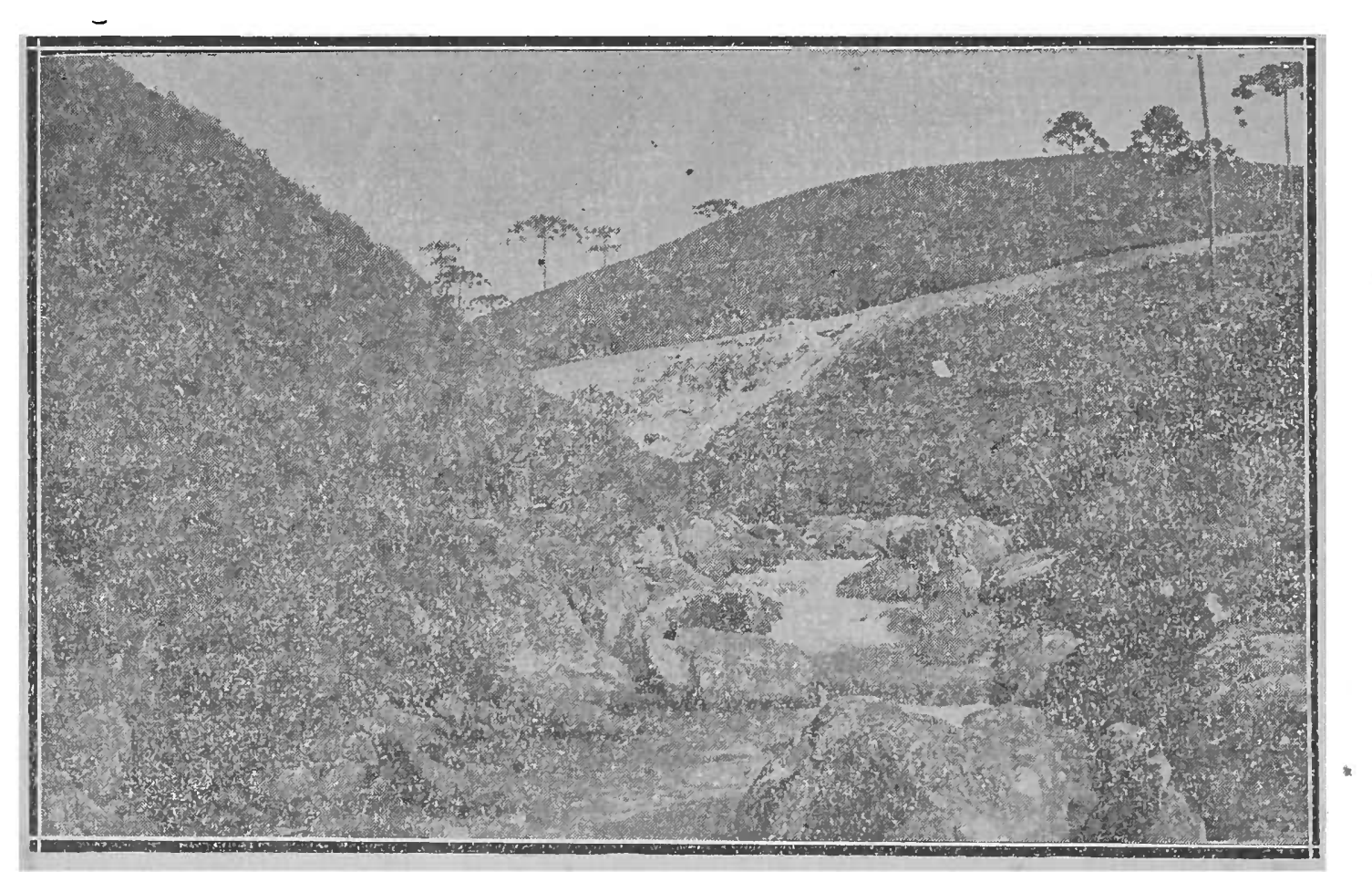

Vista de Campos do Jordão 


\section{6}

Conhecendo estas qualidades de Campos do Jordão o senador Sampaio Vidal aprezentou ha alguns anos no senado paulista um projéto criando a Prefeitura Sanitaria de Campos 'do Jordão e concedendo um emprestimo de 3 mil contos á empreza que empregasse outros 3 mil contos na construção de um Sanatorio moderno para tuberculozos e um hotel confortavel para vizitantes.

Mos o projéto não passou. E Campos do Jordão continua abandonado. Sem a minima higienề. Não ha esgotos. Ainda ha latrinas formadas de buracos. Cazas mal construidas; sem higiene nemi conforto. Pensões infectadas recebem individuos não contaminados. As cazas -onde morrem tuberculozos são imeditamente ocupadas sem prévia dezinfecção. Não ha fiscalização sanitaria.

E' lastimavel. E principalmente perigozo.

Cabe ao Governo proteger a rejião e.torná-la apta à sẹrvir de TIZICOPOLES.

Paulo de Godoy

\section{ANUNCIEM na "REVISTA de MEDICINA"}

MEDIANTE PEDIDO ENVIAMOS TABELAS DE PREÇOS E PRESTAMOS PRONTAMENTE QUAESQUER OUTRAS INFORMIAÇŎES 


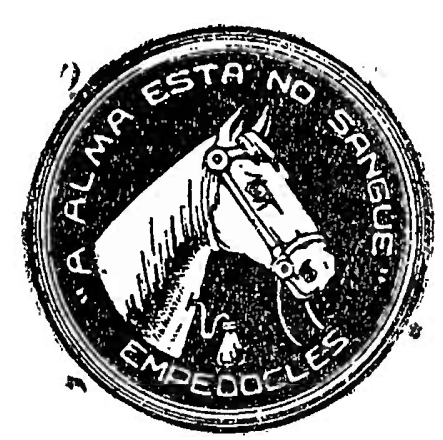

\section{Soro Hormonicos do Dr. Aché (SEXOS SEPARADOS) \\ Approvado pelo Departamento Nacional da Saude Publica}

Os Soros Hormonicos e a opiníão da distincta Classe Medica Paulista

Prof. Dr. Rubião Meira - Rua Frei Caneca, 22, em 9 de Agosto de 1926.

Conheço onze especies de soros e os que mais applico ๘ão os soros ,Hormandrico, Hormonico e Hormothyroidino. Os resultados observados tem sido bons. De todos o que melhores resultados tem me dado, é o soro Hormonico, maxime em mulheres nervosas.

Dr. Ricciotti Alegretti - Av. Luiz Antonio 87, em 2 de Agosto de 1926.

Applico constantemente os soros Hormonico, Hormocerebrino, Hormomercurialino e Hormandrico e os resultados que tenho obtido são sempre bons.

Dr. Barbosia de Barros - Rua Anchieta 4, em Agosto de 1926. Conheço todos os soros do Laboratorio de Hormotherapia e tenho obtido bons resultados com a sua applicação.

Df. Dutra de Oliveira - da Casa de Saude Santa Rita em 9 de Agosto de 1926.

Applico alguns soros do Laboratorio de Hormotherapia e os resultados que tenho obtid ${ }_{0}$ com a sua applicação são bons.

Dr. J. A. de Mesquita Sampa, 10 - Rua Jo'sé Antonio Coelho, 37, em 3 Julho de 1926.

Emprego todos os soros do Laboratorio do Horomtherapia de Aché, Travarissis \& Cia. applicando mais o soro Hormandrino. Co mo soro Hormonico em casos de fraqueza geral, tenho obtido bons resultados.

Dr. Mario Margatrido Filho - B. Itappetininga 52, em 25 de Julho de 1926.

Appliquei em minha elinica o soro Hormarsenicalino de sexos separados e obtive bons resultados.

Dr. João Hamati - Iubero Badaró, 46, em 26 de Junho de 1926.

Conheço os soros Hormonicos, masculino e feminino do Laboratorio de Hormotherapia de A.ché, Travassos \& Cia. e os resultados são bons.

Dr. Raul Marganido - B. Itapetinlinga 52, em 25 de Junho de 1926.

Conheço os soros, Hormopancreatino, Hormomercurialino e Hormarsenicalino, sendo que o que mais applico o soro Hormoarsenicalino e sempre com bon $_{S}$ resultados.

Dr. Domingos M. Rezende - General Ozorio 26, em 21 de Agosto de 1926.

Tenho empregado os soros Hormonicos do Laboratorio de Hormotherapia de Aché, Travassou \& Cio. no tratamento das neurasthenias com bons resulitados. 